\title{
The previously unbelievable performance of ultrafast thin disk lasers (Presentation Video)
}

\section{Ursula Keller}

Ursula Keller, "The previously unbelievable performance of ultrafast thin disk lasers (Presentation Video)," Proc. SPIE 8966, Vertical External Cavity Surface Emitting Lasers (VECSELs) IV, 896602 (7 March 2014); doi: $10.1117 / 12.2048382$

SPIE. Event: SPIE LASE, 2014, San Francisco, California, United States 


\title{
The Previously Unbelievable Performance of Ultrafast Thin Disk Lasers (Presentation Video)
}

\author{
Ursula Keller, ETH Zurich (Switzerland)
}

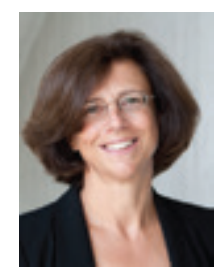

\begin{abstract}
Average power scaling in a thin disk geometry supports more than $<10 \mathrm{~kW}$ from $\mathrm{Yb}$-doped solid-state and $<100 \mathrm{~W}$ from vertical emitting semiconductor lasers. Both lasers can be passively mode-locked with SESAMs pushing the performance frontier into a regime previously assumed to be impossible. A Yb-YAG thin disk laser generates femtosecond pulses with more than $80 \mu \mathrm{J}$ pulse energy without any external pulse amplification. With semiconductor thin disk lasers (also referred to as VECSELs and MIXSELs) we can obtain $<1 \mathrm{~W}$ average power with both femtosecond and picosecond pulses and a pulse repetition rates ranging between $100 \mathrm{MHz}$ to $100 \mathrm{GHz}$.
\end{abstract}

View presentation video on SPIE's Digital Library: http://dx.doi.org/10.1117/12.2048382 